\begin{tabular}{|l|l|l||}
\hline \multicolumn{2}{|c|}{ PublisherInfo } \\
\hline \hline PublisherName & $:$ & BioMed Central \\
\hline \hline PublisherLocation & $:$ & London \\
\hline \hline PublisherImprintName & $:$ & BioMed Central \\
\hline \hline
\end{tabular}

\title{
Report from 16 year UK breast screening trial
}

\begin{tabular}{|l|l|l||}
\hline \multicolumn{2}{|c|}{ ArticleInfo } \\
\hline \hline ArticleID & $:$ & 3605 \\
\hline \hline ArticleDOI & $:$ & $10.1186 /$ bcr-1999-66584 \\
\hline \hline ArticleCitationID & $:$ & 66584 \\
\hline \hline ArticleSequenceNumber & $:$ & 25 \\
\hline \hline ArticleCategory & $:$ & Paper Report \\
\hline \hline ArticleFirstPage & $:$ & 1 \\
\hline \hline ArticleLastPage & $:$ & 4 \\
\hline \hline & & RegistrationDate : 1999-6-14 \\
\hline ArticleHistory & $:$ & OnlineDate \\
\hline \hline ArticleCopyright & $:$ & Current Science Ltd1999-6-14 \\
\hline \hline ArticleGrants & $:$ & \\
\hline \hline ArticleContext & $:$ & 1305811 \\
\hline \hline
\end{tabular}




\section{Keywords}

population screening, mammography, self examination, breast neoplasm

\section{Introduction}

The UK Trial of Early Detection of Breast Cancer (TEDBC) was set up in 1979 to investigate the effect on mortality of both mammographic screening in combination with clinical examination, and education about breast self examination. Set in eight geographical areas in England and Scotland, two centres carried out mammographic screening with clinical examination, two taught breast self examination, and four served as comparison centres with no intervention. After a mean 6.6 years of follow up, breast cancer mortality was $14 \%$ lower in the two populations offering screening than in the comparison populations ( $20 \%$ when adjusted for pre-trial differences in mortality). The effectiveness of screening younger women has been much debated. Previously in this trial, at ten years of follow up, there was no significant difference in the screening-induced mortality reduction between younger (aged 45-59 years at trial entry) and older (aged 50+ years at entry) women. Here, additional women were recruited to the study at age 45 years for a further 6 years. Mortality after 16 years of follow up in these younger women can now be reported.

\section{Aims}

To report mortality results following either mammographic screening combined withclinical examination or education about breast self examination after 16 years of followup. The effect of age at entry to programme on mortality reduction was also studied.

\section{Comments}

Although there is general agreement that mammographic screening for women aged 50-64 is beneficial, the effectiveness of screening younger women is more controversial. The $35 \%$ reduction in mortality in women aged 45-49 reported here is certainly an impressive effect of screening. However, the method of screening used here is considerably more intensive than the once-every-3-years screening by mammography alone currently offered to women aged 50-64 in the national screening programme. 
Lowering the screening age in the UK is just one of a number of options currently under consideration by the national programme, as is increasing the upper age limit. As with all screening interventions, the costs must be balanced against the potential benefit. Currently, the UK Coordinating Committee for Cancer Research is investigating the effectiveness of screening women starting at age 40 . It would be inadvisable to alter national policy and screen women aged under 50 until the results of this trial have been fully evaluated and the true benefit in screening women of this age has been demonstrated.

\section{Methods}

Two screening centres invited women aged 45-64 annually for 7 years, alternatingbiennial screening by mammography in conjunction with clinical examination, withclinical examination only. Two breast self examination centres offered women in the same age range the opportunity to attend an education session on self examination. Breast cancer death rates in women aged 45-74 were compiled for the period 1969-78 for each district, by 10 year age group. Pre-trial standardised mortality ratios were calculated for each district, the standard being the rate for all centres combined, in order to adjust for possibleconfounding factors. Observed deaths in each centre were compared with expected numbers, assuming no difference in mortality between centres after adjusting for 5-year age bandand year in trial.

\section{Results}

Overall, 45,607 women aged 45-64 years at entry (including 22,889 women aged 45-49 years) wererecruited at the screening centres, 63,373 (including 34,405 women aged 45-49) at thebreast self examination centres and 127,123 women (including 70,193 women aged 45-49)at the comparison centres. The overall invasive cancer detection rate at first screening was 4.1 per 1000 and at rescreening was 2.7 per 1000 . The invasive cancer detection rate for screening by clinical examination alone was 1.0per 1000, with 4\% in situlesions. In 16 years of follow up, a total of 360 breast cancer deaths occurred amongst women at the screeningcentres, 661 at the breast self examination centres and 1312 in the comparison centres. The expected number of deaths after adjusting for age and period in trial were 445.3, 612.9 and 1274.8, respectively. Thus, for screening centres, after adjustment for age, period in trial and pre-trial mortality rate, the ratios of observed to expected deaths in trial centres compared with comparison centres indicated a $27 \%$ decrease in breast cancer mortality. There was no significant decrease in mortality in thetwo self examination centres combined, although there was a significant $21 \%$ reductionin mortality in one centre. Analysis by age at trial entry showed no significantdifference in rate ratios between age groups at 16 years of follow up, with a significant $30 \%$ reduction in mortality in the screening group aged 45-49 at trial entry. In women inthis group aged 45 and 46 , this reduction rose to $35 \%$. Age made little difference to the rate ratios in the breast self examination centres. Analysis of cumulative mortality showed that rates started to diverge in the screening and comparison centres at around 5-6 years from the start of the trial and continued to year 16. For women aged 45-49, divergence occurred around year 3-4 after the start of the trial. 


\section{Discussion}

These results show a long-term effect of biennial screening by mammography incombination with clinical examination on breast cancer mortality. In women in the initial cohort, breast cancer mortality was $27 \%$ lower in the screening centres than in the comparison centres at 16 years of follow up. In the current study, there was no significant difference in effect of screening between different groups by age at entry. The rate ratio of breast cancer deaths was lowest for women aged 45-49, and the absolute reduction in numbers of deaths in this group was actually greater than that for women aged 50-54 at entry. This did not appear to be due to an initial excess of breast cancer mortality in the youngest age group as was observed elsewhere. Previous analysis of the trial data have suggested that clinical examination did not greatly add to the detection rates at mammographic screening. It is possible, however, that clinical examination had proportionately more effect in the younger age group. Detection rates at clinical screenings were relatively consistent across age groups whereas detection rates for mammography increased with age. The difference in results between the two breast self examination centres persists after 16 years of follow up, thus the effectiveness of breast self examination remains unclear. The results presented here confirm a long-term benefit of screening as conducted in TEDBC. Analysis of results by age confirm that screening women aged 45-49 using biennial mammography in conjunction with clinical examination is at least as effective as that for women aged over 50, and a mortality difference due to screening begins to appear after only 3-4 years.

\section{Additional information}

Data from 14 years of follow up from the Edinburgh trial are also reported in this issue of The Lancet.

\section{References}

1. Valero V, Buzdar AU, Theriault RL, Azarnia N, Fonseca GA, Willey J, Ewer M, Walters RS, Mackay B, Podoloff D, Booser D, Lee LW, Hortobagyi GN: 16-year mortality from breast screening in the UK Trial of Early Detection of Breast Cancer. Lancet. 1999, 353: 1904-1914. 